\title{
Plumbing the Depths: The Changing (Socio-Demographic) Profile of UK Poverty
}

\author{
DANIEL EDMISTON \\ School of Sociology and Social Policy, University of Leeds, \\ e-mail: D.Edmiston@leeds.ac.uk
}

\begin{abstract}
Official statistics tend to rely on a headcount approach to poverty measurement, distinguishing 'the poor' from the 'non-poor' on the basis of an anchored threshold. Invariably, this does little to engage with the gradations of material hardship affecting those living, to varying degrees, below the poverty line. In response, this paper interrogates an apparent flatlining in UK poverty to establish the changing profile of poverty, as well as those most affected by it. Drawing on the Family Resources survey, this paper reveals an increasing depth of poverty in the UK since 2010, with bifurcation observable in the living standards of different percentile groups below the poverty line. In addition, this paper demonstrates substantial compositional changes in the socio-demographic profile of (deep) poverty. Since 2010, the likelihood of falling into deep poverty has increased for women, children, larger families, Black people and those in full-time work. Within the context of COVID-19, I argue there is a need to re-think how we currently conceptualise poverty by better attending to internal heterogeneity within the broader analytical and methodological category of 'the poor'. Doing so raises pressing questions about the prevailing modes of poverty measurement that tend to frame and delimit the social scientific analysis of poverty, as well as the policies deemed appropriate in tackling it.
\end{abstract}

Keywords: poverty gap; depth of poverty; relative poverty; poverty profile; social security; destitution

\section{Introduction}

Social enquiry into relative poverty is currently faced with an ostensive contradiction. Research suggests we are witnessing increased material hardship and destitution amongst those most vulnerable to socio-economic and welfare state restructuring in liberal welfare regimes such as the UK (Bassel and Emejulu, 2017). This is perhaps unsurprising given that such contexts have typically been characterised by residual public social assistance, high commodification and market-based poverty alleviation strategies. Whilst there is non-trivial diversity in the varieties of liberalism at play, English-speaking democracies have converged on increasingly restrictive social transfers that have undermined the living standards of low-income citizens over the last decade (Deeming, 2017). Despite this, official statistics tell a story of remarkable stability in relative 
poverty rates across the same contexts with only minor or temporary upticks for particular groups in recent years (DWP, 2020a).

How then can the acute financial hardships engendered through welfare revisioning and late capitalist transformation be squared with a relative stasis in rates of relative poverty? In great part, minor fluctuations or declining rates of relative poverty are an artefact of methodological limitation. The relative poverty line is a somewhat arbitrary one that counts all those falling below a given threshold (usually $50 \%$ or $60 \%$ of median incomes), which reveals little about the changing income dynamics, socio-demographics or concentrations of poverty (Sen, 1981; Veit-Wilson, 1998). Equally, it runs the risk of obscuring fluctuations in the substantive living standards of those falling below the poverty threshold by anchoring this to (potentially stagnating) median incomes. Within the context of COVID-19 and stagnant or falling median incomes, these ongoing limitations are all the more acute. Despite these cautionary axioms, there is still a tendency within academic and policy analysis to characterise this threshold approach as a definition of poverty, rather than measuring a particular distribution of below-average incomes. Such slippage between conceptual definition and methodological categorisation leads to an attenuated analysis of poverty, reduced to technical thresholds and subject to limitations of both methodology and data (Lister, 2021). If the methods we choose to measure poverty come to determine how we understand what it is (and who counts as 'poor') then researchers find themselves in a situation where the methodological tail is wagging the conceptual dog. This matters because dominant measures of poverty invariably guide how we come to appraise and understand 'the problem', as well as the policies deemed appropriate or necessary in tackling it ${ }^{1}$.

In this paper, it is not my intention to detract from the measurement of relative poverty and its widespread utility in poverty analysis or policy evaluation. Rather, I aim to explore heterogeneity within this category to establish changes in the composition and depth of poverty witnessed since 2010. Doing so demonstrates the distinctive merits of different approaches to poverty measurement and how these can be combined to gain a fuller picture of lowincome realities and trends. In many respects, a unitary theory of poverty is problematic in light of its multi-dimensional nature and any approach to poverty measurement should also reflect and respect this reality. There is a rich history of doing so that can be traced back to the first systematic surveys of poverty in the UK. Charles Booth pioneered a poverty line approach but also deployed statistical methods and ethnographic observations to identify degrees of privation, including its correlates and underlying determinants. Criticising the lack of empirical and policy attention being given to the changing structure and determinants of 'extreme poverty' within advanced capitalist economies, the United Nations Special Rapporteur on 'extreme poverty' and human rights recently 
recommended such an undertaking during an official country visit to the UK (Alston, 2018: 15).

In response, this paper seeks to refine our conceptual, methodological and policy understanding of 'the poor' in terms of measurement and composition. Three lines of enquiry highlight the importance of doing so, exposing gaps in what we currently know about the profile and depth of poverty. First, research into the 'poverty gap' - the average distance low-income households fall from the poverty threshold - comes some way to track aggregate changes in the depth of poverty, and evidence suggests that the poverty gap for families and children has increased since 2010 (Lee, 2020). That said, this measure relies on an overall average anchored to the poverty threshold and is therefore unable to fully capture inequality 'below the line'. Second, academic and policy analysis has examined the systematic over-representation of women, children, Black, Asian and minority ethnic (BAME) groups and disabled people in poverty. However, less attention has been given to how these social differences intersect with concentrations of poverty. This seems particularly important if we are to better understand how 'social difference' is articulated in relation to the material social locations of people across the entirety of the income distribution, not just on either side of a given threshold. Third, recent efforts have been made to estimate the extent of 'destitution' in particular regions by drawing on local surveys to construct national estimates (Bramley et al., 2016). The findings of these studies suggest there are hidden degrees of hardship that are not being captured through conventional methods of poverty measurement associated with household income surveys. Given the uneven impacts of COVID-19 on livelihoods, these gaps highlight a need to go beyond poverty measures currently dominant in the UK and beyond.

Whilst attempts have recently been made to explore heterogeneity below the poverty line, 'urgent research is needed to better understand the experiences and outcomes of people who are measured as being more than 50\% below the poverty line' (SMC, 2019: 23). With that in mind, this paper seeks to answer the following questions: How has the profile and depth of poverty changed in the UK since 2010? And how are these trends related to the changing socio-demographic characteristics of 'the poor'? Drawing on data from the Family Resources survey, I demonstrate that there has been a splintering in the economic fortunes of different percentile and sociodemographic groups falling towards the bottom of the income distribution. The findings demonstrate the need to deploy a plurality of approaches to poverty measurement, to better understand how and why people move, not just 'in' and 'out' of (extreme) financial hardship, but also through it along a continuum of disadvantage. The paper concludes by reflecting on what this means for poverty analysis and alleviation. 


\section{Background and Policy Context}

Depending on the particular dimension foregrounded, the concept of relative poverty can be an imperfect but common proxy for identifying (A) a lack of financial means for human welfare (B) systemic exclusion from mainstream social practices; (C) material or resource deprivation whereby individuals lack access to certain items or activities deemed necessary; or (D) a combination of all three (Bradshaw and Finch, 2003). Each of these traditions within poverty studies is rooted in a conception of disadvantage that seeks to foreground a particular feature of its character, cause or effect. All nonetheless attempt to capture the relative nature of poverty and better understand this in relation to the 'rest of society'. In doing so though, binary demarcations between those above and below a given 'threshold' (usually $60 \%$ of median incomes) risk glossing over much of the heterogeneity that exists below the relative poverty line (Figure 1). Such an approach risks ascribing a unilateral condition or experience to the entirety of the broader category of 'the poor' (a sizeable portion of the income distribution), without recognising how income poverty functions in a scalar (or even vector) relationship with questions of 'human welfare', 'participation' and 'inclusion'. Indeed, it might be reasonably assumed, but is subject to empirical investigation, that households furthest from the relative poverty threshold are not only likely to be experiencing (D) but in a qualitatively different sense to those closer to the poverty line.

Since the 2007-08 global financial crisis, a great deal of attention has been paid to the changing profile of income inequality with efforts made to explore gradations of advantage amongst 'the rich'. However, we have not witnessed the same efforts to explore degrees of disadvantage. Whilst it is beyond the remit of this paper to examine the qualitative significance of a changing poverty profile, I do explore the relativity of financial hardship that bears on the lives of those living, to varying degrees, below the poverty line ${ }^{2}$. It is hoped doing so affords fuller insight into the distributional effects of socio-economic and welfare state restructuring.

Since 2010, reforms to the tax-benefit system have reduced the coverage and generosity of low-income, working-age social security in the UK. Over the last decade, Crisis Loans, the Child Trust Fund, Education Maintenance Allowance, as well as elements of Child Tax Credit and Working Tax Credit have been abolished. The phased introduction of Universal Credit (UC) is gradually consolidating six working-age benefits into a single payment to 'incentivise' work and streamline the claims-making process. Much less generous than its original formulation, those towards the bottom (10\%) of the income distribution have lost most (Brewer et al., 2019). Delayed payments and sanctioning have also presented significant risks to the economic security of low-income households. Between 2014-16, uprating for certain benefits (including elements of Tax Credits (TC) and Child Benefit) moved from the Retail Price Index to 


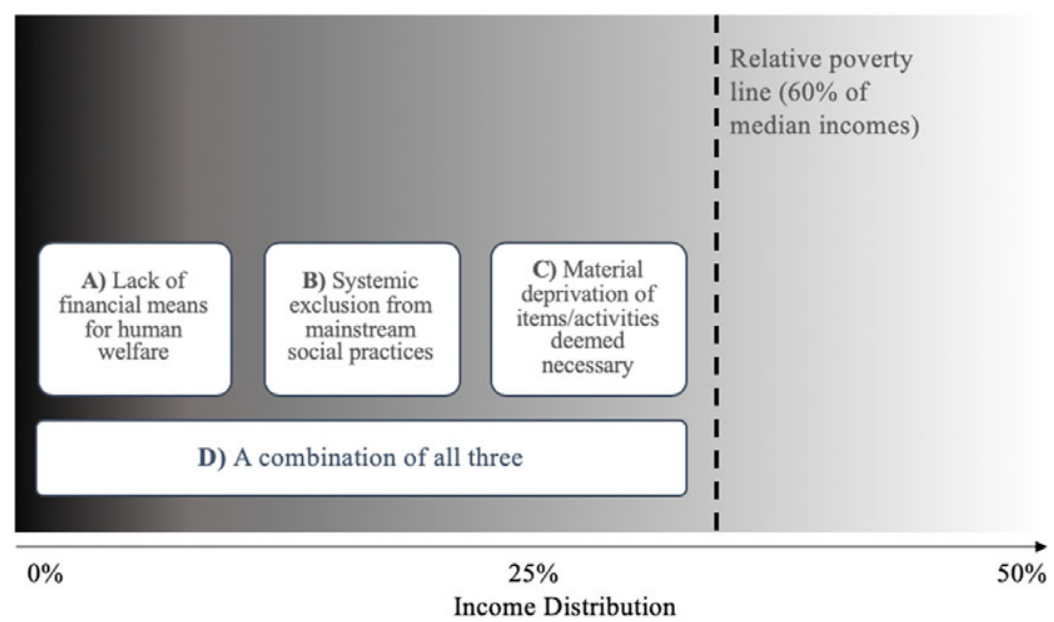

Figure 1. Conceptualising relative poverty: categorical vs. continuum

Consumer Price Index. In 2016, the majority of working-age benefits were frozen for four years, along with tax credits and local housing allowances. Local rent limits and under-occupancy penalties have been introduced for certain groups in social housing. A benefit cap has been introduced (and subsequently

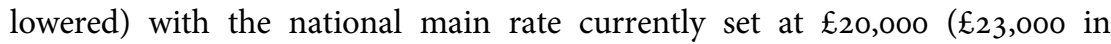
London). In 2017, a two-child limit was introduced which means UC will only provide support for a maximum of two children for certain families. The full impact of this is yet to be felt with the effects being cumulative for larger families. Breaking the link between entitlement and need, the result of these changes is a substantive decline in 'the adequacy of income support' for many low-income households with benefit levels falling further away from average earnings and minimum income standards since 2010 (Hirsch, 2020: 218).

Particularly for larger low-income families, these changes are 'guaranteed to increase poverty depth' (Bradshaw and Keung, 2019: 11; Lee, 2020). The distributional effects of this are, in many respects, well-rehearsed. Academic and grey literature demonstrates the highly regressive nature of welfare recalibration whereby changes have damaged the living standards of those toward the bottom of the income distribution most ${ }^{3}$. For example, distributional analysis demonstrates that those in the $1^{\text {st }}$ and $2^{\text {nd }}$ deciles of the income distribution are likely to lose around $20 \%$ of their incomes as a result of tax and benefit changes (Resolution Foundation, 2020: 50). Many have also highlighted how these cuts are heavily gendered and racialised in ways that are routinely glossed over (Bassel and Emejulu, 2017; Hall et al., 2017).

Since 2010, many have forecast that 'the likely outcome is an increase in poverty and inequalities in the next few years' (Taylor-Gooby, 2012: 78). And yet, rates of relative poverty for the whole population have flatlined (with 
isolated upticks for smaller population subgroups) (DWP, 2020a). There are a number of reasons for this that do not exclusively concern the working-age population or indeed the economic resources available to low-income households (Bourquin et al., 2019). However, one possibility is that those worst affected by welfare reforms may already have been below the poverty line before taxbenefit changes took effect. This is all the more likely given that those disproportionately exposed to the negative effects of social security cuts (very low-income households, working-age adults and children) are most prone to 'persistent poverty' (SMC, 2019). Looking ahead, there is evidence to suggest that those furthest away from the poverty line are worst affected by COVID-19 in terms of employment and pay (SMC, 2020). Crisis social security measures have helped temper some of the worst effects for the 'poorest families' through uprating, easements and additions. However, many of these changes are temporary, partial or ineffectual for households claiming legacy benefits or affected by the benefit cap and two child-limit. If the uprating to UC and TC standard allowance is not made permanent, the poorest households stand to lose $7 \%$ of their annual income on average in 2021 (Handscomb, 2020).

Against this backdrop, threshold approaches to poverty analysis that focus exclusively on rates as opposed to degrees of financial hardship will (continue to) fail to fully capture the changing living standards of low-income households in the years to come. Situating more recent developments within their historical context, this limitation is clearest looking at rates of 'absolute' and 'relative' poverty over time. In 1994/95, 24\% of individuals were living on less than $60 \%$ of contemporary median household incomes (after housing costs) (DWP, 2020a). Following a widespread expansion in means-tested benefits for low-income families in the early years of New Labour, this fell to $22 \%$ in 2002/03. However, it has not really moved since and currently stands at $22 \%$ according to the latest available figures (DWP, 2020a). As we might expect, rates of 'absolute' poverty fell considerably between the mid 1990 and mid 200os: from $41 \%$ of individuals living on less than $60 \%$ of $2010 / 11$ median household incomes (held constant in real terms) in $1994 / 95$, to $22 \%$ in $2002 / 03$ suggesting an improvement in the living standards of low-income individuals. Since then however, rates of progress have been limited and stood at 20\% in 2018/19 (DWP, 2020a).

In the UK and further afield, reforms have either been introduced or proposed to develop alternative indicators of poverty within official statistics to more effectively capture realities, causes and effects believed to shape lowincome dynamics (Francis-Devine, 2020). In part, this is motivated by a long-standing concern about the validity of dominant methods of measurement and, in particular, their capacity to capture extreme poverty (Bradshaw and Movshuk, 2019). In response, there are a range of approaches seeking to better understand the intensity of poverty. The most obvious approach is to use a lower 
poverty threshold but this ultimately suffers from the same methodological limitations as a higher threshold measure. Alternatives include the World Bank $\$ x$ per day indicator, severe deprivation indices and thresholds set relative to social assistance, minimum income standards or reference budgets. Each of these measures have distinctive benefits and limitations but have all been used to measure aspects of extreme poverty across time and space (Bradshaw and Movshuk, 2019, Lister 2021). The most widely used indicator of poverty intensity across advanced capitalist economies is currently the 'poverty gap' indicator which measures how far people fall, on average, from the poverty line. Bradshaw and Keung (2019) evidence increases in the absolute and relative poverty gap for households with children in the UK since 2010 and argue cuts to social security entitlement have undermined the minimum income scheme previously available. More recently, poverty depth has also been assessed through the 'low income gap' which measures the average distance people fall from a socially agreed minimum income standard (Hirsch et al., 2020). Whilst instructive, these approaches tend to track aggregate trends which, as demonstrated later in this paper, presents particular difficulties if bifurcation in the living standards of low-income households is observed.

Finally, an increasingly popular approach is to combine multiple indicators. For example, the Europe 2020 'at risk of poverty or social exclusion' indicator is a composite measure of income poverty, severe material deprivation of items and activities, and work intensity, that seeks to capture the multidimensional character, causes and effects of disadvantage. Composite indicators such as this are most effective as capturing multiple dimensions and degrees of poverty at the same time. However, this paper focuses exclusively on income indicators to assess changing living standards. I do so mindful of the limitations associated with such an approach (discussed later in this paper). I am nonetheless keen to focus on the proxies of disadvantage currently used in official poverty statistics that are perhaps less contested and have greatest (apolitical) currency across research, policy and practice. Policies such as the UK Welfare Reform and Work Act that sought to move away from income-based measures have been widely criticised for conflating definitions of poverty with some of the causes and correlates of it (e.g. Stewart and Roberts, 2018). Such developments nonetheless reflect growing political and policy concern that anti-poverty interventions are failing to identify and target 'hard-to-reach' groups, most in need of public assistance. As a result, there has been a broader movement to better understand and target 'vulnerable' low-income households - especially workless families with children - through improvements to data collection, analysis and policy intervention (DWP, 2017). Lessons from (and shortcomings in) these initiatives have fuelled applied and theoretical interest in the dominant methods of poverty measurement that tend to frame and delimit the social scientific analysis of poverty. 


\section{Data and Methodology}

This paper presents analysis based on data from the Family Resources Survey (FRS) which is used to produce national statistics on poverty and inequality in the UK (DWP, 2020b). This survey offers a uniquely rich dataset on levels and sources of income, as well as household and socio-demographic characteristics. The FRS has been conducted continuously since 1992, with a large representative sample of around 19,000 households for each year. I draw on the Households Below Average Income (HBAI) dataset which includes derived variables drawing on underlying data from the FRS (DWP, 2020c). All findings concerning 'income' refer to weekly net disposable income after housing costs: as a better approximation of living standards. Nominal values are presented in $2018 / 19$ prices. Unless otherwise stated, the unit of analysis is based on individual level data. However, incomes are measured at the household level and equivalised using the OECD modified equivalence scale (cf. Karagiannaki and Burchardt, 2020).

Bivariate analysis is undertaken to establish the changing economic security and characteristics of individuals in the bottom 5 th, 10th, 20th, 30 th percentiles of the income distribution between 2010/11 and 2018/19 (the latest available year). These percentiles are not used as alternative 'thresholds' or 'definitions' of poverty, but as instructive indicators to establish varying degrees of privation in two ways. First, to explore real terms nominal and relative changes in the living standards of individuals falling within and between different interval (percentile) groups over time. Second, to examine how socio-demographic characteristics are related to changes in the resources and position of different groups across the low-income distribution. The results outline trends in the living standards of different interval groups, and the changing depth of poverty for social groups most exposed to it.

The term 'deep poverty' is used here to refer to those falling in the bottom $10 \%$ of the income distribution. Such categorisation is obviously subject to the same limitations as any other cut-off point but is used here as part of a broader strategy to explore compositional changes within and across low-income interval groups. Whilst the term deep poverty is often inconsistently applied, it is anticipated that individuals falling within this group are not only likely to be experiencing (D), but in a qualitatively different sense to those closer towards the relative poverty threshold (Figure 1). This is of course subject to empirical investigation, but if true stands to nuance a categorical understanding of relative poverty that is currently widespread. There are also a number of methodological motivations for focusing on the bottom $10 \%$ that concern the accurate measurement of living standards towards the very bottom of the income distribution. Previous research suggests household survey data on the very bottom (1-3\%) of the income distribution are susceptible to biases in non-response, sample attrition and benefit under-reporting (Bramley et al., 2016; Brewer et al., 
2017; Corlett et al., 2018). For example, inadequate correspondence between incomes and expenditure and numerous risks associated with measurement error (Meyer et al., 2009). For this reason, the inclusion of the lowest-income cases in FRS analyses has previously been brought into question (Bramley et al., 2016: 10). That said, the FRS does offer the best available data: growth in 'benefit and tax credit incomes are similar in administrative and FRS data over time' (Bourquin et al., 2019: 7). In addition, Brewer et al. (2017) find that incomes and expenditure monotonically increase from the $2^{\text {nd }}$ percentile of the income distribution and begin to better reflect actual living standards. With this in mind, a conservative approach has been taken to exclude the bottom $3 \%$ of cases when measuring nominal and relative income changes for the bottom $5 \%$ of the income distribution unless otherwise stated. This follows the convention of the Department for Work and Pensions and makes it possible to measure outcomes of those that are a significant distance from the poverty line, without compromising on data quality and thus inferences possible (DWP, 2020a).

The analysis is divided into three parts. First, I present descriptive statistics on the changing incomes of different interval groups towards the bottom of the income distribution. Second, I present bivariate analysis on differences in the socio-demographic characteristics of those falling in different interval groups. Third, results from multiple logistic regression are discussed to compare the risk of falling into deep poverty across different socio-demographic groups over time. Model 1 includes time period only for the two years under consideration: 2010/11 and 2018/19. In Model 2, I add socio-demographic predictor variables in a stepwise fashion to assess the extent to which period differences could be the result of an altered composition of the overall population. In Models 3-8, I explore interaction terms with period to establish whether the sociodemographic composition and labour market engagement of those falling into deep poverty has changed since $2010 / 11$. To enhance interpretability and to provide a more parsimonious model, sociodemographic predictor variables such as age, ethnicity and labour market engagement have been collapsed from more detailed categorisations so that there are fewer parameters to model interaction effects. BAME data in the bivariate analysis are based on three-year averages (2009/10-2011/12) because single year estimates are considered too volatile for smaller ethnic minority groups (DWP, 2020c). However, logistic regressions only draw from single-year estimates as the models are based on larger ethnic minority categories for the two years under consideration. To address the problem of unobserved heterogeneity in logistic regression, $y$-standardisation of the logit coefficient $(B)$ has been undertaken in Appendix 1 (Mood, 2010). Here, odds ratios $(\operatorname{Exp}(B))$ have been rescaled to make them more comparable within and across nested models. In light of ongoing debate about whether such rescaling is necessary (Kuha and Mills, 2018), unstandardized summary results are also available in Table 4. All findings draw on analyses of weighted estimates. 


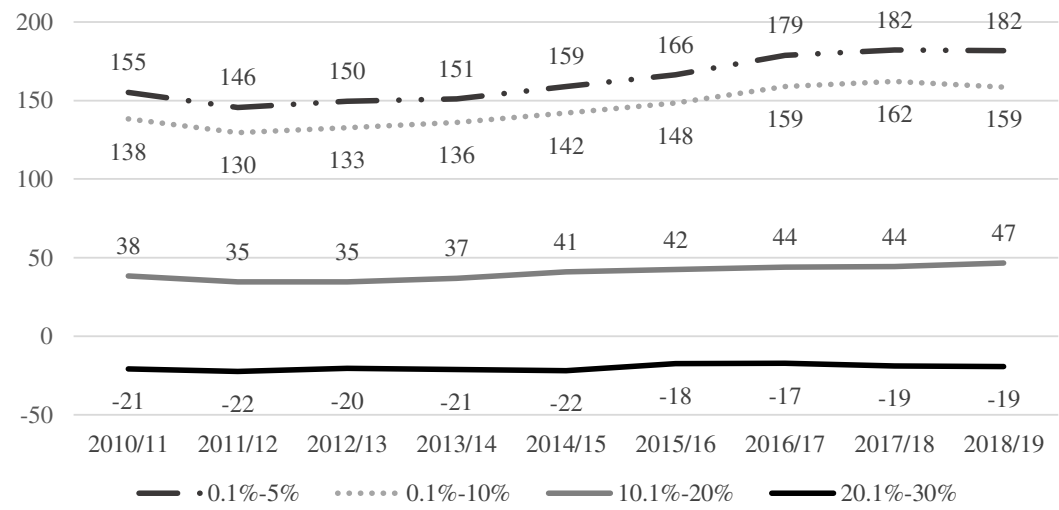

Figure 2. Nominal gap between median income of interval groups and the relative poverty line (AHC, Epw equivalised 2018/19 prices)

\section{Results}

\section{How has the profile and depth of poverty changed since 2010?}

The equivalised poverty line (after housing costs) increased from $\mathfrak{E}_{253}$ to $\mathfrak{E}_{2} 68$ between 2010/11 and 2018/19. However, the very poorest have seen their average incomes fall further away from this line since 2010. For individuals in the bottom $5 \%$ and $10 \%$ of the income distribution, the nominal gap between median incomes and the poverty line has grown by $17 \%$ and $15 \%$ respectively (Figure 2) $)^{4}$. For those closest to the poverty line (in the $2^{\text {nd }}$ and $3^{\text {rd }}$ decile of the income distribution) their incomes have kept better pace with real terms increases in the poverty threshold. As a ratio, this means that the average (median) value of incomes for the bottom 5\% has fallen from $39 \%$ to $32 \%$ of the poverty line between $2010 / 11$ and $2018 / 19$ and from $45 \%$ to $41 \%$ for those in the bottom $10 \%$ over the same period (Figure 3). By contrast, the income ratios for those in the $2^{\text {nd }}$ and $3^{\text {rd }}$ decile have remained relatively stable. The result is a nominal and relative reduction in the resources available to those towards the very bottom, with those closer to the poverty line seeing their incomes remain reasonably stable in comparison.

Situating these trends within a broader context, Figure 4 summarises the percentage change in average incomes of different interval groups and demonstrates varied fluctuation in low-income living standards over time. Since 2007/ 08 , those towards the bottom ( $5 \%$ and $10 \%)$ of the income distribution have experienced a substantive reduction in average incomes, whilst those closer to the poverty line ( $2^{\text {nd }}$ and $3^{\text {rd }}$ deciles) have experienced modest increases. However, these trends are particularly pronounced from 2011 onwards. In part, this is explained by a staged divergence in the economic fortunes of different income interval groups in the wake of the 2007/08 global financial crisis. Average incomes of the lowest income groups initially fell but subsequentlty 


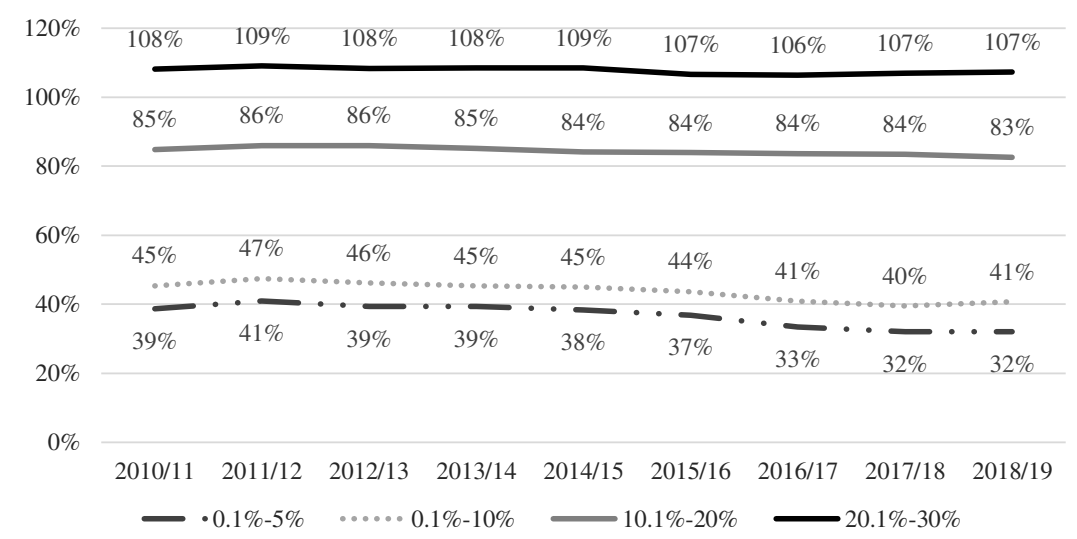

Figure 3. Median incomes of interval groups as a ratio of relative poverty line (AHC, $\mathfrak{E p w}$ equivalised 2018/19 prices)

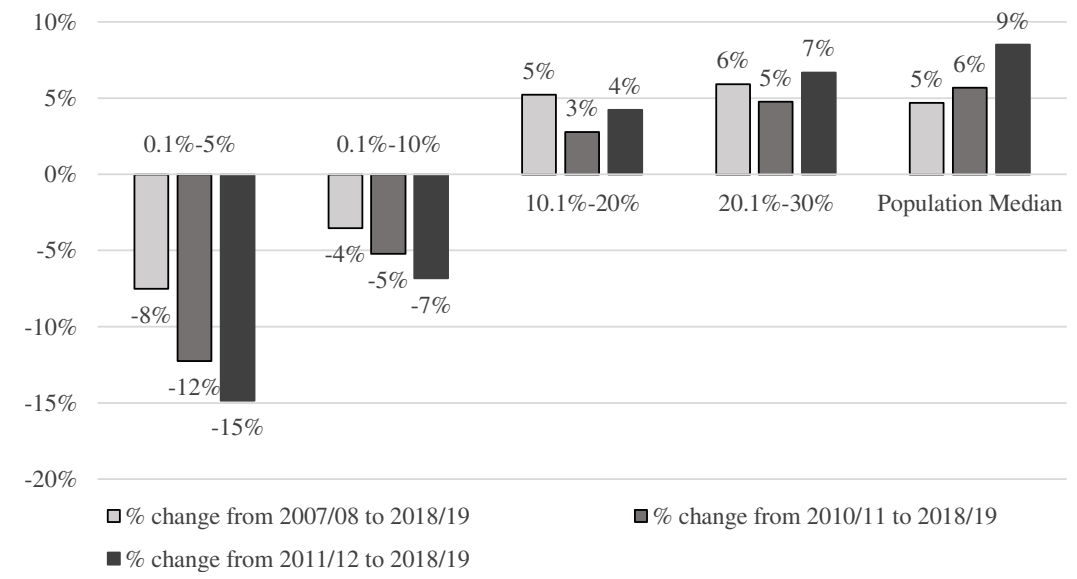

Figure 4. Percentage change between median incomes of interval groups, 2007/08-2018/19 (AHC, Epw equivalised 2018/19 prices)

recovered whilst average incomes for those closer to the poverty line stagnated but then began to catch up with median incomes in earnest. As a result, a more dramatic bifurcation in the living standards of low-income individuals is observable from 2011. Between 2011/12 and 2018/19, those in the bottom 5\% and $10 \%$ of the income distribution witnessed a reduction in their average incomes by $15 \%$ and $7 \%$, whilst average incomes for those in the $2^{\text {nd }}$ and $3^{\text {rd }}$ deciles increased by $4 \%$ and $7 \%$ respectively. These trends co-incide with a series of changes to the tax-benefit system (implemented from 2011 onwards) that many have previously argued regressively impact on the livelihoods of low-income households (e.g. Resolution Foundation, 2020: 50). However, the trends presented here 
demonstrate that the very poorest are losing most with other low-income individuals experiencing relative increases that come closer to keeping pace with median incomes. Alongside differential labour market engagement trends, those in the $2^{\text {nd }}$ and $3^{\text {rd }}$ decile have been less exposed (at least in relative terms) to social security changes implemented since 2010, compared to those in the bottom $10 \%$ of the income distribution (Bourquin et al., 2019; Gardiner, 2019).

Between 2010/11 and 2018/19, equivalised median incomes for the overall population grew from $\mathfrak{E}_{422}$ to $\mathfrak{4}_{446}$. At the same time, average (mean) disposable incomes fell considerably for the lowest income groups (Table 1). This means that those in the bottom $5 \%$ of the income distribution saw their annual incomes fall by $£_{548}$ on average between $2010 / 11$ and $2018 / 19$. By contrast, those in the 2nd and 3 rd deciles saw their annual incomes increase by $£ 269$ and $\mathfrak{E} 667$ on average respectively during the same period.

A consequence of these trends is that an increasing proportion of lowincome households are falling further away from the poverty line. Returning to a broader view, the proportion of households falling more than $50 \%$ below the poverty line grew from $28.4 \%$ to $32.8 \%$ between $2007 / 08$ and $2018 / 19$ (Table 2). Over the same period, the proportion of households falling more than $75 \%$ below the poverty line increased from $15.1 \%$ to $17.1 \%$. Since 2010 , the proportion of low-income households falling more than $50 \%$ below the poverty line has grown by an estimated 2.6 percentage points.

In sum, there has been a splintering in the economic fortunes of different interval groups falling towards the bottom of the income distribution. Thus far, these trends have not been fully captured because current attempts to measure poverty depth rely on average incomes for all those falling below a given threshold to compare this against nominal or ratio trends. Measures that focus exclusively on these aggregate changes inevitably gloss over dispersion within the broad category of 'the poor'. Often used as a measure of poverty depth, the 'poverty gap' is one such indicator that risks underestimating the full extent to which there has been a deepening of poverty because it does not account for potential bifurcation in the economic resources available to low-income households at different interval groups. Whilst this may result in an underestimation of current trends, other approaches seeking to capture poverty depth that fail to account for this may actually lead to a misrepresentation of current trends. For example, in 2019 the UK Social Metrics Commission, a key proponent of alternative and additional poverty measures, argued that the depth of poverty had changed very little since 2000 (SMC, 2019). An official briefing from the House of Commons library, reporting on poverty depths concluded that 'on average, people living below the poverty line have moved closer towards it' (Francis-Devine, 2020: 39). Such conclusions underline the need to a) better measure and report on heterogeneity 'below the line' in poverty analysis, and 
TABLE 1. Mean and Standard Deviation of Equivalised Disposable Income by Interval Groups (AHC, Epw equivalised 2018/19 prices)

\begin{tabular}{|c|c|c|c|c|c|c|c|}
\hline & 2010/11 Mean & $2010 / 11 \mathrm{SD}$ & 2018/19 Mean & $2018 / 19$ SD & Mean Difference $(\mathrm{Xi}-\mathrm{X} \mathrm{j})$ & Effect Size Cohen's $d$ & $\begin{array}{l}\text { Annual change in } \\
\text { incomes }\end{array}$ \\
\hline $20.1 \%-30 \%$ & 274.4 & 16.2 & 287.2 & 18.5 & 12.8 & 0.7 & $\mathfrak{E 6 6 7}$ \\
\hline $10.1 \%-20 \%$ & 214.0 & 19.2 & 219.2 & 22.2 & 5.2 & 0.2 & $\mathfrak{E 2 6 9}$ \\
\hline $0.1 \%-10 \% *$ & 134.9 & 29.7 & 129.4 & 33.2 & -5.4 & 0.2 & $\mathfrak{E}-284$ \\
\hline $0.1 \%-5 \% *$ & 96.5 & 13.2 & 86.0 & 15.9 & -10.5 & 0.7 & $\mathfrak{E}-548$ \\
\hline
\end{tabular}

* The bottom $3 \%$ of the income distribution are excluded due to data volatility.

TABLE 2. Distribution of households falling varying proportions below the relative poverty line (AHC)

\begin{tabular}{|c|c|c|c|c|c|c|c|}
\hline & $\begin{array}{l}\text { Households Below } \\
\text { Poverty Line }\end{array}$ & $\begin{array}{l}0.1 \%-10 \% \text { below } \\
\text { line }\end{array}$ & $\begin{array}{l}10.1 \%-25 \% \\
\text { below line }\end{array}$ & $\begin{array}{l}25.1 \%-50 \% \\
\text { below line }\end{array}$ & $50 \%+$ below line & $\begin{array}{l}50.1 \%-75 \% \\
\text { below line }\end{array}$ & $75 \%+$ below line \\
\hline $2007 / 08$ & $5,738,963$ & $19.2 \%$ & $24.0 \%$ & $28.4 \%$ & $28.4 \%$ & $13.3 \%$ & $15.1 \%$ \\
\hline $2010 / 11$ & $5,646,957$ & $18.5 \%$ & $24.8 \%$ & $26.4 \%$ & $30.3 \%$ & $15.3 \%$ & $14.9 \%$ \\
\hline $2018 / 19$ & $6,145,623$ & $18.1 \%$ & $22.7 \%$ & $26.4 \%$ & $32.8 \%$ & $15.8 \%$ & $17.1 \%$ \\
\hline \multirow{2}{*}{\multicolumn{2}{|c|}{$\begin{array}{c}\text { \% point change } \\
2010 / 11-2018 / 19 \\
\text { [Confidence Intervals] }\end{array}$}} & $-0.4 \%$ & $-2.1 \%$ & $0.0 \%$ & $2.6 \%$ & $0.5 \%$ & $2.1 \%$ \\
\hline & & {$[-1.1 \%$ to $0.2 \%]$} & {$[-2.8 \%$ to $-1.4 \%]$} & {$[-0.8 \%$ to $0.7 \%]$} & [1.8\% to $3.4 \%]$ & {$[-0.2 \%$ to $1.1 \%]$} & [1.5\% to $2.8 \%]$ \\
\hline
\end{tabular}


b) refine existing poverty depth indicators to capture low-income dynamics over time.

\section{How has the socio-demographic profile of (deep) poverty changed since 2010?}

The systematic over-representation of particular social groups in poverty is well-documented. However, examination of this phenomenon has often treated poverty as a categorical condition which particular social groups are more or less likely to fall into. Such an approach to both material and social axes of division can be productive for establishing how certain groups fare relative to others, and the wider standards prevailing. However, as observed in the previous section, economic disadvantage is neither unilateral nor linear, and methods that treat it as such risk obscuring or misrepresenting trends. This does not render a systemic examination of the relationship between poverty and social difference impossible. However, it does require a more fine-grained conceptualisation of financial hardship: one that avoids relying on or reproducing a binary understanding of disadvantage. With this in mind, I now explore how degrees of poverty intersect with markers of social difference across the entirety of the low-income distribution, not just on either side of a given threshold.

In Tables 3 and 4, I present an overview of how the socio-demographic composition of (deep) poverty has changed since 2010. These tables detail the proportion of particular social groups represented in the whole population, in relative poverty, and in the bottom three deciles of the income distribution in 2010/11 and 2018/19. Through simple cross-tabulations, I explore nominal and ratio changes in the incidence of (varying degrees of) poverty accounting for broader demographic and labour market trends. Results summarised in Tables 3 and 4 confirm that the incidence of relative poverty is much higher amongst children, women, BAME groups, those affected by a disability, and those that are unemployed, working part-time and living in households with 2 or more dependent children. However, bivariate analysis also reveals significant non-linear variation in the exposure of particular social groups to gradations of financial hardship since 2010. In Table 5, I present a summary of binary logistic regression analyses undertaken to compare the influence of sociodemographics on the likelihood of being in deep poverty over time. All of the socio-demographic and economic variables included had a statistically significant effect on the likelihood of being in deep poverty. However, only a selection of observations are discussed here for the sake of interpretability: I examine trends for women, children, those affected by a disability, 'race' and ethnicity, and economic status in turn.

Since 2010 , there has been an increase $(4.7 \%)$ in the proportion of women in relative poverty and a slight growth $(2.1 \%)$ in the proportion in deep poverty, but women are still relatively 'under-represented' in this group, compared to 
TABLE 3. Socio-demographic change by low-income interval groups

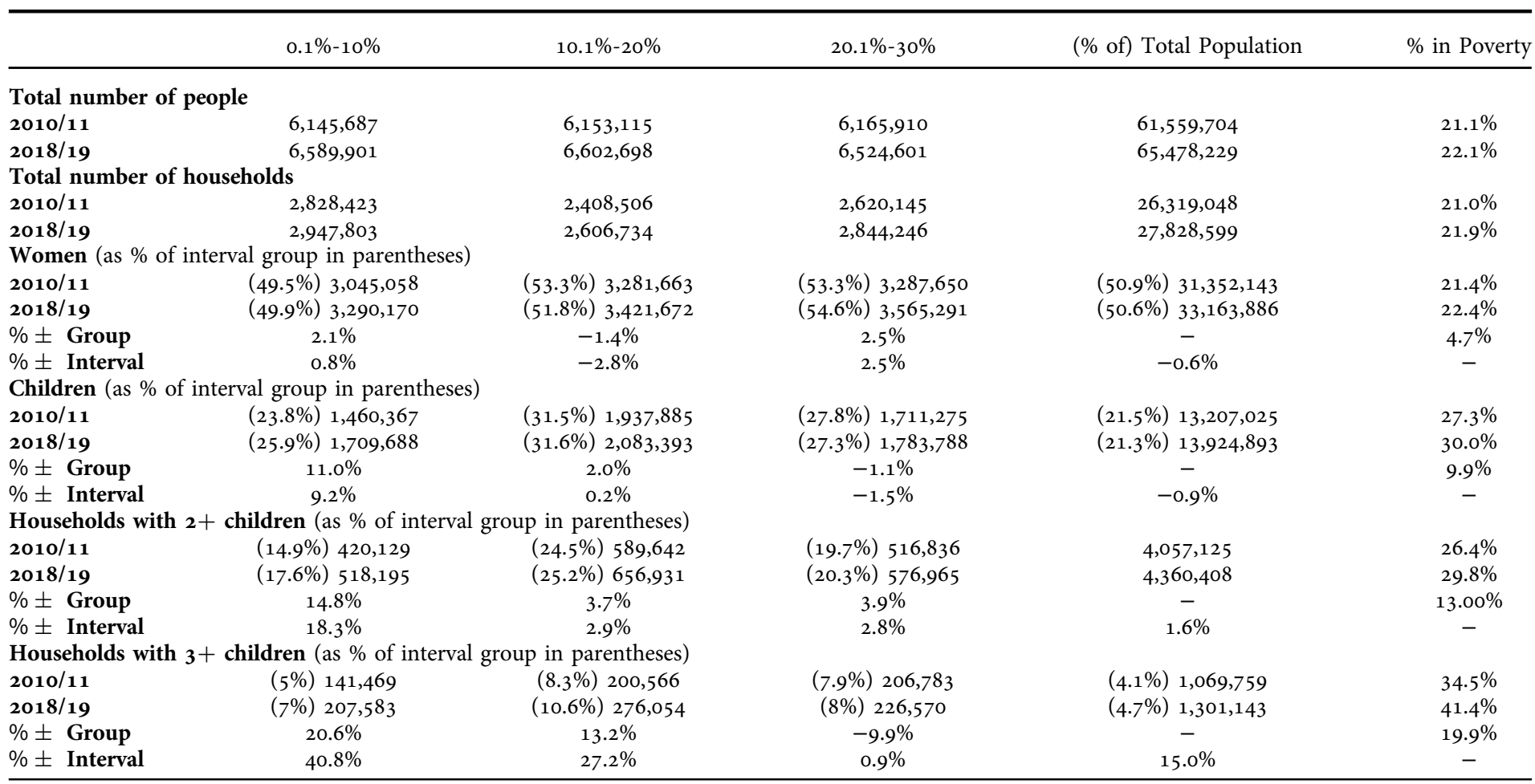


TABLE 3. Continued

\begin{tabular}{|c|c|c|c|c|c|}
\hline & $0.1 \%-10 \%$ & $10.1 \%-20 \%$ & $20.1 \%-30 \%$ & (\% of) Total Population & $\%$ in Poverty \\
\hline \multicolumn{6}{|c|}{ Affected by a disability (as \% of interval group in parentheses) } \\
\hline 2010/11 & $(31.4 \%) 1,926,759$ & $(35.3 \%) 2,171,831$ & $(39.1 \%) 2,411,172$ & $(29.6 \%) 18,198,126$ & $23.9 \%$ \\
\hline 2018/19 & $(36.6 \%) 2,411,541$ & $(43.5 \%) 2,871,646$ & $(45.2 \%) 2,946,723$ & $(34.3 \%) 22,478,329$ & $26.2 \%$ \\
\hline$\% \pm$ Group & $1.3 \%$ & $7.0 \%$ & $-1.1 \%$ & - & $9.3 \%$ \\
\hline$\% \pm$ Interval & $16.7 \%$ & $23.2 \%$ & $15.5 \%$ & $16.1 \%$ & - \\
\hline \multicolumn{6}{|c|}{ Black, Asian and Minority Ethnic people (BAME)* (as \% of interval group in parentheses) } \\
\hline 2009-12 & $(23 \%) 1,419,230$ & $(18.4 \%) 1,137,105$ & $(13.5 \%) 834,952$ & (11.1\%) $6,854,178$ & $39.4 \%$ \\
\hline 2016-19 & $(24.3 \%) 1,575,676$ & $(23 \%) 1,500,819$ & $(16.6 \%) 1,073,288$ & $(13.2 \%) 8,575,714$ & $38.6 \%$ \\
\hline$\% \pm$ Group & $-11.3 \%$ & $5.5 \%$ & $2.74 \%$ & - & $-2.0 \%$ \\
\hline$\% \pm$ Interval & $5.6 \%$ & $24.8 \%$ & $23.0 \%$ & $19.0 \%$ & - \\
\hline
\end{tabular}

* Figures are based on 3-year averages. 
TABLE 4. Socio-demographic change by low-income interval groups

\begin{tabular}{|c|c|c|c|c|c|}
\hline & $0.1 \%-10 \%$ & $10.1 \%-20 \%$ & $20.1 \%-30 \%$ & (\% of) Total Population & $\%$ in Poverty \\
\hline \multicolumn{6}{|c|}{ Pakistani* (as \% of interval group in parentheses) } \\
\hline 2009-12 & (4\%) 249,858 & $(4.6 \%) 281,136$ & $(2.6 \%) 163,082$ & $(1.7 \%) 1,044,576$ & $52.3 \%$ \\
\hline 2016-19 & (4\%) 261,780 & $(5.6 \%) 368,301$ & $(3.8 \%) 246,849$ & $(2.2 \%) 1,428,589$ & $48.1 \%$ \\
\hline$\% \pm$ Group & $-23.4 \%$ & $-4.2 \%$ & $10.7 \%$ & - & $-8.1 \%$ \\
\hline$\% \pm$ Interval & $-0.3 \%$ & $23.9 \%$ & $44.8 \%$ & $30.1 \%$ & - \\
\hline \multicolumn{6}{|c|}{ Bangladeshi* (as \% of interval group in parentheses) } \\
\hline 2009-12 & $(1.8 \%) 113,890$ & $(1.4 \%) 89,213$ & $(1.2 \%) 71,346$ & $(0.6 \%) 399,230$ & $54.7 \%$ \\
\hline 2016-19 & $(1.8 \%) 116,802$ & $(3 \%) 196,886$ & $(1.6 \%) 101,358$ & $(1.0 \%) 634,470$ & $52.3 \%$ \\
\hline$\% \pm$ Group & $-35.5 \%$ & $38.9 \%$ & $-10.6 \%$ & - & $-4.4 \%$ \\
\hline$\% \pm$ Interval & $-2.4 \%$ & $108.7 \%$ & $35.9 \%$ & $51.2 \%$ & - \\
\hline \multicolumn{6}{|c|}{ Black/African/Caribbean/Black British* (as \% of interval group in parentheses) } \\
\hline 2009-12 & $(5.3 \%) 330,408$ & $(3.9 \%) 243,544$ & $(3.8 \%) 235,726$ & $(2.6 \%) 1,632,283$ & $38.6 \%$ \\
\hline 2016-19 & $(6.9 \%) 444,826$ & $(5.2 \%) 339,675$ & $(4.2 \%) 272,429$ & $(3.1 \%) 1,982,350$ & $42.5 \%$ \\
\hline$\% \pm$ Group & $10.9 \%$ & $14.8 \%$ & $-4.8 \%$ & - & $10.1 \%$ \\
\hline$\% \pm$ Interval & $28.1 \%$ & $31.9 \%$ & $10.6 \%$ & $15.5 \%$ & - \\
\hline \multicolumn{6}{|c|}{ Self-employed ${ }^{* *}$ (as \% of interval group in parentheses) } \\
\hline $2010 / 11$ & $(15.4 \%) 945,829$ & $(9.2 \%) 564,797$ & $(6.9 \%) 423,857$ & $(9.9 \%) 6,120,166$ & $25.5 \%$ \\
\hline 2018/19 & $(14.9 \%) 984,665$ & $(10.7 \%) 706,755$ & $(8.8 \%) 576,642$ & $(10.2 \%) 6,647,727$ & $27.0 \%$ \\
\hline$\% \pm$ Group & $-4.2 \%$ & $15.2 \%$ & $25.2 \%$ & - & $5.9 \%$ \\
\hline$\% \pm$ Interval & $-2.9 \%$ & $16.6 \%$ & $28.6 \%$ & $2.1 \%$ & - \\
\hline \multicolumn{6}{|c|}{ Working part-time ${ }^{* *}$ (as $\%$ of interval group in parentheses) } \\
\hline $2010 / 11$ & $(13.1 \%) 803,870$ & $(12.6 \%) 774,267$ & $(12.5 \%) 773,301$ & (9.2\%) $5,652,247$ & $29.5 \%$ \\
\hline $2018 / 19$ & $(15.1 \%) 996,261$ & $(15.3 \%) \quad 1,012,794$ & $(13.1 \%) 852,017$ & (9.8\%) $6,447,740$ & $33.8 \%$ \\
\hline$\% \pm$ Group & $8.64 \%$ & $14.67 \%$ & $-3.41 \%$ & - & $14.6 \%$ \\
\hline$\% \pm$ Interval & $15.58 \%$ & $21.90 \%$ & $4.12 \%$ & $7.25 \%$ & - \\
\hline
\end{tabular}




\begin{tabular}{lcccc}
\hline & $0.1 \%-10 \%$ & $10.1 \%-20 \%$ & $20.1 \%-30 \%$ & (\% of) Total Population \\
\hline Full-time work $^{* *}$ (\% of interval group in parentheses) & & & \\
2010/11 & $(5.5 \%) 340,369$ & $(8.1 \%) 500,030$ & $(10.1 \%) 624,432$ & $(26.2 \%) 16,154,585$ \\
2018/19 & $(8.8 \%) 580,110$ & $(8.2 \%) 538,223$ & $(13.1 \%) 852,730$ & $(28.9 \%) 18,893,006$ \\
$\% \pm$ Group & $45.7 \%$ & $-8.0 \%$ & $16.8 \%$ & - \\
$\% \pm$ Interval & $58.9 \%$ & $0.3 \%$ & $29.1 \%$ & $5.6 \%$ \\
Workless** (as \% of interval group in parentheses) & & & $10.0 \%$ \\
2010/11 & $(41.3 \%) 2,538,722$ & $(34.5 \%) 2,122,382$ & $(20.1 \%) 1,240,474$ & $(13.3 \%) 8,171,804$ \\
2018/19 & $(31.7 \%) 2,087,558$ & $(22.7 \%) 1,499,728$ & $(14.0 \%) 916,377$ & $(10.6 \%) 6,951,268$ \\
$\% \pm$ Group & $-3.3 \%$ & $-16.9 \%$ & $-13.2 \%$ & - \\
$\% \pm$ Interval & $-23.3 \%$ & $-34.1 \%$ & $-30.2 \%$ & $58.9 \%$ \\
\hline
\end{tabular}

* Figures are based on 3-year averages. ** Economic status of benefit unit (ECOBU); "Self-employed" = One or more self-employed "Part-time" = No one in fulltime work and 1 or more part-time work; "Full-time Work" = Single, couple all in full-time work; "Workless" = Workless head or spouse unemployed and Workless, other inactive. 
other low-income interval groups and the rest of the population (Table 3). Variation in the gendered composition of low-income interval groups highlights the importance of complicating a standard feminisation of poverty thesis (Dermott and Pantazis, 2014). Specifically, there is a need for a gendered analysis of poverty that does not assume women's exposure to the risk of financial hardship functions in a unilinear fashion. Such an approach reveals that the increase in rates of relative poverty amongst women since 2010, is principally driven by an increasing proportion of women in deep poverty. In line with the bivariate results, Model 3 presented in Table 5, shows that the likelihood of being in deep poverty (as opposed to not being in deep poverty) is slightly lower for women than men (reference category) (odds ratio $[O R]=0.907$ ) but this gender gap is smaller in $2018 / 19(O R=1.022)$ than it was in $2010 / 11$ (reference category). This is, perhaps, unsurprising given that low-income (particularly BAME) women have been some of those worst affected by changes to the tax-benefit system since 2010 (Hall et al., 2017).

Between 2010 and 2019, the proportion of children in relative poverty increased from $27.3 \%$ to $30.0 \%$. During the same period, the proportion of children in deep poverty increased by $11.0 \%$. As a result, more than a quarter $(25.9 \%)$ of those in deep poverty are currently children (Table 3 ). The increased incidence of relative and deep poverty amongst children is particularly pronounced for children in larger families who are more likely to be affected by the two-child limit and benefit cap. Since 2010, the proportion of larger families in deep poverty has increased significantly: by $14.8 \%$ for households with $2+$ children, and by $20.6 \%$ for households with $3+$ children (Table 3 ). These results demonstrate an increasing risk and depth of poverty witnessed amongst children in the UK. Compared to pensioners (reference category), all other age groups are more likely to be in deep poverty $\left(O R_{35-64}=5.713 ; O R_{16-34}=6.544 ; O R_{0-19}=5.665\right)$. However, the likelihood of falling into deep poverty has increased most for children since 2010 ( $O R=1.225)$ (Model 4, Table 5). Depending on the number of dependent children in it, households differ in terms of their likelihood of being in deep poverty $\left(O R_{1 \text { child }}=1.054, O R_{2 \text { depchild }}=0.922, O R_{3+\text { depchild }}=0.938\right)($ Model 7 , Table 5$)$. Since 2010, the likelihood of being in deep poverty for households with one dependent child has decreased $\left(O R_{1}\right.$ child $\left.=0.909\right)$, and the lower likelihood of being in deep poverty for larger families has weakened, particularly for those with $3+$ dependent children $\left(O R_{2}\right.$ depchild $\left.=1.125, O R_{3+\text { depchild }}=1.421\right)$ (Model 7, Table 5). Despite additional COVID-19 provisions and temporary uprating, these trends are likely to continue with the benefit cap and two-child limit still in place.

Between 2010-2019, the proportion of households affected by a disability living in relative poverty increased from $23.9 \%$ to $26.2 \%$ (Table 3 ). Looking at low-income interval groups, there has also been a slight increase $(1.3 \%)$ in the depth of poverty amongst those affected by a disability (Table 3 ). The likelihood of falling into deep poverty is lower for those affected by a disability 
TABLE 5. Summary results of logistic regression for likelihood of being in deep poverty, 2010/11 and 2018/19, Odds Ratios and (Standard Errors)

\begin{tabular}{|c|c|c|c|c|c|c|c|c|}
\hline & Model 1 & Model 2 & Model 3 & Model 4 & Model 5 & Model 6 & Model 7 & Model 8 \\
\hline Constant & $0.111(.000)$ & $0.004(.002)$ & $0.004(.002)$ & $0.004(.002)$ & $0.004(.002)$ & $0.004(.002)$ & $0.004(.002)$ & $0.003(.002)$ \\
\hline Period (Ref. 2010/11) & $1.009(.001)$ & $1.095(.001)$ & $1.083(.001)$ & $0.985(.002)$ & $1.017(.002)$ & $1.023(.002)$ & $1.034(.002)$ & $1.429(.003)$ \\
\hline Sex (Ref. Male) & & $0.917(.001)$ & $0.907(.001)$ & $0.906(.001)$ & $0.907(.001)$ & $0.907(.001)$ & $0.909(.001)$ & $0.91(.001)$ \\
\hline \multicolumn{9}{|l|}{ Age (Ref. Pensionable) } \\
\hline Older working-age $(35-64)$ & & $6.185(.001)$ & $6.185(.001)$ & $5.713(.002)$ & $5.612(.002)$ & $5.618(.002)$ & $5.705(.002)$ & $5.742(.002)$ \\
\hline Younger working-age (16-34) & & $6.353(.001)$ & $6.352(.001)$ & $6.544(.002)$ & $6.205(.002)$ & $6.22(.002)$ & $6.278(.002)$ & $6.404(.002)$ \\
\hline Children (0-19) & & $6.289(.001)$ & $6.289(.001)$ & $5.665(.002)$ & $5.432(.002)$ & $5.441(.002)$ & $5.88(.002)$ & $5.952(.002)$ \\
\hline \multicolumn{9}{|l|}{ Ethnicity (Ref. White) } \\
\hline A Mixed/Multiple Ethnic Group & & $1.691(.002)$ & $1.691(.002)$ & $1.676(.002)$ & $2.194(.003)$ & $2.195(.003)$ & $2.197(.003)$ & $2.215(.003)$ \\
\hline B Asian/Asian British & & $2.199(.001)$ & $2.199(.001)$ & $2.189(.001)$ & $3.066(.001)$ & $3.066(.001)$ & $3.118(.001)$ & $3.139(.001)$ \\
\hline C Black/African/Caribbean/British & & $2.252(.001)$ & $2.251(.001)$ & $2.242(.001)$ & $2.109(.002)$ & $2.109(.002)$ & $2.12(.002)$ & $2.137(.002)$ \\
\hline D Other Ethnic Group & & $2.897(.002)$ & $2.897(.002)$ & $2.884(.002)$ & $2.919(.003)$ & $2.92(.003)$ & $2.917(.003)$ & $2.941(.003)$ \\
\hline Disability (Ref. family not affected) & & $0.849(.001)$ & $0.849(.001)$ & $0.848(.001)$ & $0.841(.001)$ & $0.846(.001)$ & $0.852(.001)$ & $0.848(.001)$ \\
\hline \multicolumn{9}{|l|}{ Dependent Children (Ref. none) } \\
\hline 1 Dependent Child in Household & & $1.007(.001)$ & $1.008(.001)$ & $1.005(.001)$ & $1.01(.001)$ & $1.01(.001)$ & $1.054(.001)$ & $1.054(.001)$ \\
\hline 2 Dependent Children & & $0.975(.001)$ & $0.975(.001)$ & $0.974(.001)$ & $0.979(.001)$ & $0.979(.001)$ & $0.922(.001)$ & $0.914(.001)$ \\
\hline $3+$ Dependent Children & & $1.135(.001)$ & $1.135(.001)$ & $1.131(.001)$ & $1.139(.001)$ & $1.139(.001)$ & $0.938(.002)$ & $0.924(.002)$ \\
\hline \multicolumn{9}{|l|}{ Employment Status (Ref. Full-time) } \\
\hline A One or more self-employed & & $6.83(.001)$ & $6.829(.001)$ & $6.83(.001)$ & $6.872(.001)$ & $6.872(.001)$ & $6.876(.001)$ & $9.352(.002)$ \\
\hline B Full-time and part-time work & & $2.461(.001)$ & $2.461(.001)$ & $2.454(.001)$ & $2.457(.001)$ & $2.458(.001)$ & $2.45(.001)$ & $2.777(.002)$ \\
\hline C Only part-time work & & $7.174(.001)$ & $7.173(.001)$ & $7.157(.001)$ & $7.202(.001)$ & $7.204(.001)$ & $7.185(.001)$ & $8.558(.002)$ \\
\hline $\begin{array}{l}\text { D Workless (Inactive/ } \\
\text { Unemployed) }\end{array}$ & & $14.959(.001)$ & $14.958(.001)$ & $14.976(.001)$ & $15.105(.001)$ & $15.105(.001)$ & $15.124(.001)$ & $18.309(.002)$ \\
\hline
\end{tabular}


TABLE 5. Continued

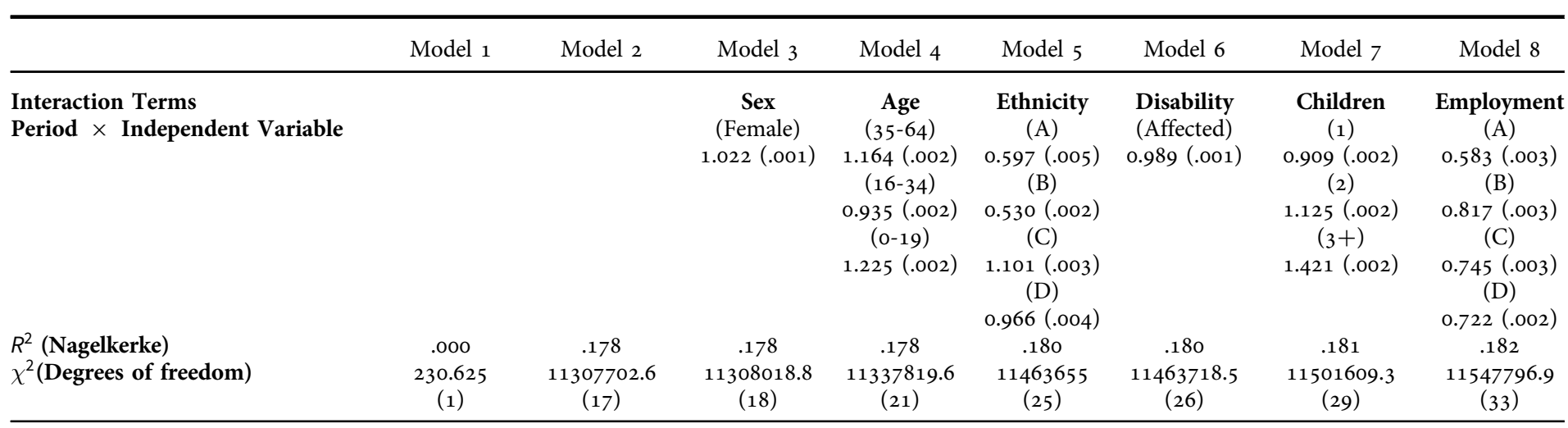

Note. Ref. $=$ reference category, all odds ratios presented are significant $\mathrm{p}<0.001, \mathrm{~N}=100,739$, Weight $=$ G_INDPP 
$(O R=0.846)$ and this is slightly more pronounced in $2018 / 19$ than it was in 2010/11 (OR=0.989) (Model 6, Table 5). However, the extent of poverty depth for those affected by a disability is likely to be underestimated given that additional disability-related costs are not reflected in calculations of disposable household income in the FRS (SMC, 2019). Since 2010, a shrinking category of disability in social security administration has reduced the coverage and generosity of benefits. In part, we can see this reflected in the disproportionate growth $(+23.2 \%)$ of those affected by a disability represented in the $2^{\text {nd }}$ decile of the income distribution (Table 3 ).

Rates of relative poverty amongst BAME individuals remain particularly high: $39.4 \%$ in 2010 reducing to $38.6 \%$ in 2019 (Table 3). Alongside this, there have been compositional changes in the ethnic profile of the low-income population that are not in line with those observed in the wider general population. There has been an increase in the representation of BAME individuals in the bottom 3 deciles of the income distribution, but relative increases are particularly pronounced closest to the poverty line in the $2^{\text {nd }}$ and $3^{\text {rd }}$ deciles $(+24.8 \%$ and $+23 \%$ ). Despite only making up $13.2 \%$ of the overall population, almost a quarter $(24.3 \%)$ of those in deep poverty were BAME in 2019 (Table 3). Model 5 in Table 5 shows that the likelihood of being in deep poverty is significantly lower for White groups (reference category) than it is for Mixed $(O R=2.194)$, Asian $(O R=3.066)$, Black $(O R=2.109)$ and Other Ethnic $(O R=2.919)$ groups.

However, interaction terms show that such racial and ethnical inequalities became less pronounced for those identifying as Mixed $(O R=0.597)$, Asian $(O R=0.530)$ or Other Ethnic group $(O R=0.966)$ between 2010 and 2019 (Model 5, Table 5). A particularly pronounced periodic effect witnessed amongst Asian individuals is also reflected in descriptive trends. In Table 4, rates of relative poverty are shown to have fallen amongst Pakistani and Bangladeshi individuals (albeit from a very high place) since 2010. Accounting for changes in the ethnic composition of the overall population, there has been a substantial reduction in the proportion of Pakistani and Bangladeshi individuals in deep poverty: falling by $23.4 \%$ and $35.5 \%$ respectively. The extent of this improvement differs across the low-income distribution though with the representation of Pakistani individuals increasing $(+44.8 \%)$ closer to the poverty line (in the $3^{\text {rd }}$ income decile) and representation of Bangladeshi individuals increasing considerably $(+108.7 \%)$ in the $2^{\text {nd }}$ income decile ${ }^{5}$. Compared to all other ethnic groups, Black individuals have fared worst in terms of their economic security since 2010 . Beyond an increased rate of relative poverty (from $38.6 \%$ to $42.5 \%$ ), the proportion in deep poverty has grown considerably by $10.9 \%$ (Table 4 ). As a result, over a fifth $(22.4 \%$ ) of all Black people are currently in deep poverty. Model 5 in Table 5 confirms that the likelihood of being in deep poverty for Black people is stronger $(O R=1.101)$ in 2019 than it was in 2010. 
For employment status, the results from Model 8 in Table 5 demonstrate there are significant differences in the likelihood of being in deep poverty depending on the type and degree of labour market engagement. Those living in households comprising full-time work (reference category) are much less likely to be in deep poverty than those whose household economic status is self-employed $(O R=9.352)$, a mixture of full-time and part-time employment $(O R=2.777)$, only part-time work $(O R=8.558)$, or workless $(O R=18.309)$. That said, full-time work appears to have become less effective at protecting against deep poverty. Since 2010, the likelihood of being in deep poverty has fallen for other types of employment compared to those in full-time work (e.g. $O R_{\text {self-employed }}=0.583, O R_{\text {workless }}=0.722$ ).

In part, this is explained by an intrinsic increase in working poverty in the UK whereby the poorest have seen the biggest increase in employment rates in recent years ${ }^{6}$. For example, rates of relative poverty amongst those living in fulltime working households grew slightly from $5.6 \%$ to $6.6 \%$ between 2010 and 2019 (Table 4). During the same period, the proportion of people living in full-time working households in deep poverty jumped considerably by $45.7 \%$ (Table 4$)$. In addition to this, there has been a substantial reduction $(-23.3 \%)$ in the representation of workless households in deep poverty between 2010 and 2019 (Table 4). However, the most substantial reduction has been the representation of workless households that fall in the $2^{\text {nd }}$ and $3^{\text {rd }}$ deciles of the income distribution: $-34.1 \%$ and $-30.2 \%$ respectively. Since 2010 , the risk and depth of poverty has increased significantly for those living in part-time working households: a third are currently in relative poverty and the proportion in deep poverty has grown by $8.6 \%$ (Table 4 ). Overall, it appears there are not just limits to which work provides a meaningful route out of poverty (Hick and Lanau, 2018), but also a route out of deep poverty.

\section{Discussion and Conclusion}

In this paper, I have outlined trends in the changing economic security of those living, to varying degrees, below the poverty line. Since 2010, there has been a bifurcation in the living standards of low-income citizens in the UK. Those closest to the poverty line have seen relative improvements in their incomes. At the same time, there has been a deepening and intensification of financial hardship for those towards the very bottom of the income distribution with the proportion of people falling $75+\%$ below the poverty line growing by $14.8 \%$ since 2010 (Table 2). These changes in the economic profile of poverty have also occurred alongside substantive shifts below the poverty line that are reconfiguring the socio-demographic composition of (deep) poverty. Despite ostensive progress in reducing rates of relative poverty amongst particular social groups, markers of social difference are intersecting with gradations of financial hardship in ways 
that are non-linear but nonetheless systematic. The likelihood of being in deep poverty has increased for women, children, larger families, Black people, and those in full-time work since $2010^{7}$.

In light of the findings, it is worth reflecting on a key limitation of using household income surveys to measure changes in the depth and (sociodemographic) composition of poverty. Namely, that the increasing depth and socio-demographic diversity of poverty is likely to be underestimated. This is for three reasons. First, Corlett et al. (2018: 50) warn 'of the UK's population of 66 million, 1.2 million are outside the scope of the FRS' because only those in private households are sampled. Trends then, suggesting an increasing depth of poverty, are likely to be underestimated as 'some groups at high risk of destitution may also be over-represented in the categories of non-response, missing data and sample attrition' (Bramley et al., 2016: 10). Second, the full impact of tax and benefit changes will not yet be reflected in available FRS data. The fouryear freeze to working-age benefits began in $2015 / 16$ so the cumulative significance of this is only currently observable for three years of available data: we can therefore reasonably anticipate an increasing depth of poverty in future data releases. Third, the depth of poverty is likely to be more pronounced once (gendered) intra-household inequalities are taken into account (Karagiannaki and Burchardt, 2020).

Despite these limitations, evidence on the changing poverty profile and socio-demographic composition of those below the poverty line can be brought to bear on established debates concerning poverty categorisation, measurement and analysis in four ways. First, to encourage critical reflection on how and what we should measure when it comes to researching 'the poor' and what this means for dominant analytical and methodological frameworks within poverty studies. Second, to refine our theoretical understanding of poverty and the extent to which 'human welfare', 'participation' and 'inclusion' can be understood as either present or absent in the lives of (extremely) low-income households. This is particularly important for fleshing out a conception of poverty that accounts for the relational gradations of 'agency', 'autonomy' and 'welfare' that mediate the lives of low-income households. Such an approach makes it possible to establish how and why people move, not just 'in' and 'out' of financial hardship, but also 'through' it along a continuum of disadvantage. This should encourage poverty researchers to examine what, if anything, is distinctive about deep poverty and the wider continuum of disadvantage it sits within. A third, and related, avenue of research is to capitalise on the additional dimensions of description and social explanation that a non-categorical measure of financial hardship brings. Doing so makes it possible to identify what underlies a clustering or dispersion of low incomes and what affects the likelihood of falling into deep poverty over time through the use of panel data. Fourth, to better 
understand how 'social difference' is articulated in relation to the material social locations of people, across the entirety of the income distribution, not just on either side of a given threshold. Within the current context, these agendas for poverty research present an opportunity to better understand, explain and address the full distributional effects of tax-benefit changes implemented since 2010 and the COVID-19 pandemic.

The findings of this paper also raise questions for policy and practice when it comes to poverty alleviation. In terms of official statistics, the results demonstrate how dominant methods of poverty measurement are not currently fit for purpose. That is, they fail to fully capture the (socio-demographic) composition and depth of poverty which invariably constrains the capacity of social policy to both understand and tackle it. In particular, it is clear that the 'poverty gap' indicator that is often used to analyse poverty depth needs to be used alongside measures such as those presented in this paper to account for and track potential bifurcation in the living standards of low-income households below the poverty line. It is also clear that a pluralistic approach to poverty measurement is needed: one that recognises the distinctive merits and limitations of particular indicators of financial hardship. To gain the fullest picture of changes in the profile and depth of poverty, a range of measures need to be used in tandem to capture nominal and relative dimensions across the entirety of the low-income distribution. In an era of constrained public social spending, this matters for identifying which tax-benefit changes can most effectively and efficiently mitigate against (deep) poverty. This presents a number of challenges for how policy evaluation and design (e.g. equality impact assessments and targeted means-testing) might respond to varying degrees and dimensions of financial hardship whilst implementing poverty alleviation measures that are practicably feasible. In the wake of COVID-19, this will become increasingly important given that the very poorest individuals are likely to be worst affected by the pandemic (SMC, 2020) and certain key groups (such as those with No Recourse to Public Funds) have been overlooked by government protections and provisions.

\section{ACKNOWLEDGEMENTS}

Parts of this paper were made possible by funding received through a UKRI rapid response grant: ES/Voo3879/1. Many thanks to the editors and two reviewers for their helpful feedback on earlier drafts of this work. Thanks also to Jonathan Bradshaw, Ruth Lister and Albert Varela for their guidance and encouragement with this paper. Any errors remaining are my own.

\section{Supplementary material}

To view supplementary material for this article, please visit https://doi.org/10. $1017 /$ So0 47279421000180 


\section{Notes}

1 Similarly, poverty (alleviation) policy routinely frames our particular understanding of financial hardship and its underlying determinants.

2 As argued by Summers (2020: 594), there are methodological and ethical risks in not delineating between individual research subjects and 'the wider social groups(s) to which they are understood to belong' (and indeed further challenges in understanding what it means to 'belong to' a given social group).

3 Some of these trends have been partially offset by real terms increases in the minimum wage and labour market participation.

4 As discussed in the methodology, reported incomes for the bottom $5 \%$ exclude cases for the bottom $3 \%$ and this applies to Figures 2-4.

5 To speculate on the drivers behind this trend, the employment rate for Pakistani and Bangladeshi individuals grew by $23.9 \%$ compared to by $7.1 \%$ for the overall population between 2010-2018 lifting many out of deep poverty but not low incomes (GOV.UK, 2020).

6 There are also a number of exogenous reasons for this (cf. Bourquin et al., 2019).

7 A notable exception to this, is the reduction in relative and deep poverty experienced by BAME groups overall and Pakistani and Bangladeshi people in particular.

\section{References}

Alston, P. (2018), Statement on Visit to the United Kingdom, by Professor Philip Alston, United Nations Special Rapporteur on extreme poverty and human rights, London: The Office of the High Commissioner for Human Rights.

Bassel, L. and Emejulu, A. (2017), Minority women and austerity: Survival and resistance in France and Britain: Policy Press.

Bourquin, P. et al. (2019), Why has in-work poverty risen in Britain?, London: Institute for Fiscal Studies.

Bradshaw, J. and Finch, N. (2003), 'Overlaps in dimensions of poverty', Journal of Social Policy, 32(4): 513-525.

Bradshaw, J. and Keung, A. (2019), 'UK child poverty gaps are still increasing', Poverty, 162 (Winter 2019). Available at: https://cpag.org.uk/sites/default/files/files/resource/ CPAG-UK-child-poverty-gaps-are-still-increasing-Poverty162.pdf

Bradshaw, J. and Movshuk, O. (2019), 'Measures of extreme poverty applied in the European Union', in H. Gaisbauer, G. Schweiger and C. Sedmark (eds.), Absolute Poverty in Europe, pp 39-69.

Bramley, G. et al. (2016), Destitution in the UK - Technical Report, Edinburgh: Heriot-Watt University.

Brewer, M., Etheridge, B. and O'Dea, C. (2017), 'Why are households that report the lowest incomes so well-off?', The Economic Journal, 127(605): F24-F49.

Brewer, M. et al. (2019), Universal credit and its impact on household incomes: the long and the short of it, London: Institute for Fiscal Studies.

Corlett, A., Clarke, S., D'arcy, C., et al. (2018), The Living Standards Audit 2018, London: The Resolution Foundation.

Deeming, C. (2017), 'The Lost and the New 'Liberal World'of Welfare Capitalism: A Critical Assessment of Gøsta Esping-Andersen's The Three Worlds of Welfare Capitalism a Quarter Century Later', Social Policy and Society, 16(3): 405-422.

Dermott, E. and Pantazis, C. (2014), 'Gender and Poverty in Britain: Changes and Continuities between 1999 and 2012', Journal of Poverty and Social Justice, 22(3): 253-269.

DWP (2017), Improving Lives: Helping Workless Families, London: Department for Work and Pensions.

DWP (2020a), Households Below Average Income: An analysis of the UK income distribution: 1994/95-2018/19, London: Department for Work and Pensions. 
DWP (2020b), Family Resources Survey, 2018-2019. [data collection], UK Data Service.

DWP (2020c), Households below average income (HBAI): quality and methodology report 2018/ 19. London: Department for Work and Pensions.

Francis-Devine, B. (2020), Poverty in the UK: statistics, London: HMSO.

Gardiner, L. (2019), The shifting shape of social security: Charting the changing size and shape of the British welfare system, London: Resolution.

Hall, S. et al. (2017), 'Intersecting inequalities: The impact of austerity on Black and Minority Ethnic women in the UK', London: Runnymede and Women's Budget Group.

Handscomb, K. (2020), Safe Harbour? Six key welfare policy decisions to nevigate this winter, London: Resolution Foundation.

Hick, R. and Lanau, A. (2018), 'Moving in and out of in-work poverty in the UK: An analysis of transitions, trajectories and trigger events', Journal of Social Policy, 47(4): 661-682.

Hirsch, D. (2020), 'After a decade of austerity, does the UK have an income safety networth its name?', in J. Rees, M. Pomati and E. Heins, (eds.), Social Policy Review 32: Analysis and Debate in Social Policy, 2020. Bristol: Policy Press.

Hirsch, D., et al. (2020), 'The low income gap: a new indicator based on a minimum income standard', Social Indicators Research, 149: 67-85.

Karagiannaki, E. and Burchardt, T. (2020), Intra-household inequality and adult material deprivation in Europe, London: CASE, LSE.

Kuha, J. and Mills, C. (2018), 'On group comparisons with logistic regression models', Sociological Methods \& Research, 0049124117747306.

Lee, T. (2020), Dragged Deeper: How families are falling further and further below the poverty line, London: Child Poverty Action Group.

Lister, R. (2021), Poverty, 2nd Edition, Cambridge: Polity Press.

Meyer, B. D., Mok, W. K. and Sullivan, J. X. (2009), The under-reporting of transfers in household surveys: its nature and consequences: National Bureau of Economic Research.

Mood, C. (2010), 'Logistic regression: Why we cannot do what we think we can do, and what we can do about it', European Sociological Review, 26(1): 67-82.

Resolution Foundation (2020), New Chancellor. BIG Budget Spring Budget 2020 response, London: Resolution Foundation.

Sen, A. (1981), Poverty and famines: an essay on entitlement and deprivation, Oxford: Clarenden Press.

SMC (2019), Measuring Poverty 2019, London: Social Metrics Commission.

SMC (2020), Poverty and COVID-19, London: Social Metrics Commission.

Stewart, K. and Roberts, N. (2018), 'Child poverty measurement in the UK: assessing support for the downgrading of income-based poverty measures', Social Indicators Research, 142: 523-542.

Summers, K. (2020), 'For the greater good? Ethical reflections on interviewing the 'rich'and 'poor'in qualitative research', International Journal of Social Research Methodology, 23(5): 593-602.

Taylor-Gooby, P. (2012), 'Root and Branch Restructing to Achieve Major Cuts: The Policy Programme of the 2010 UK Coalition Government', Social Policy \& Administration, 46(1): 61-82.

Veit-Wilson, J. (1998), Setting adequacy standards: How governments define minimum incomes. Bristol: Policy Press. 